\title{
(b) CABI
}

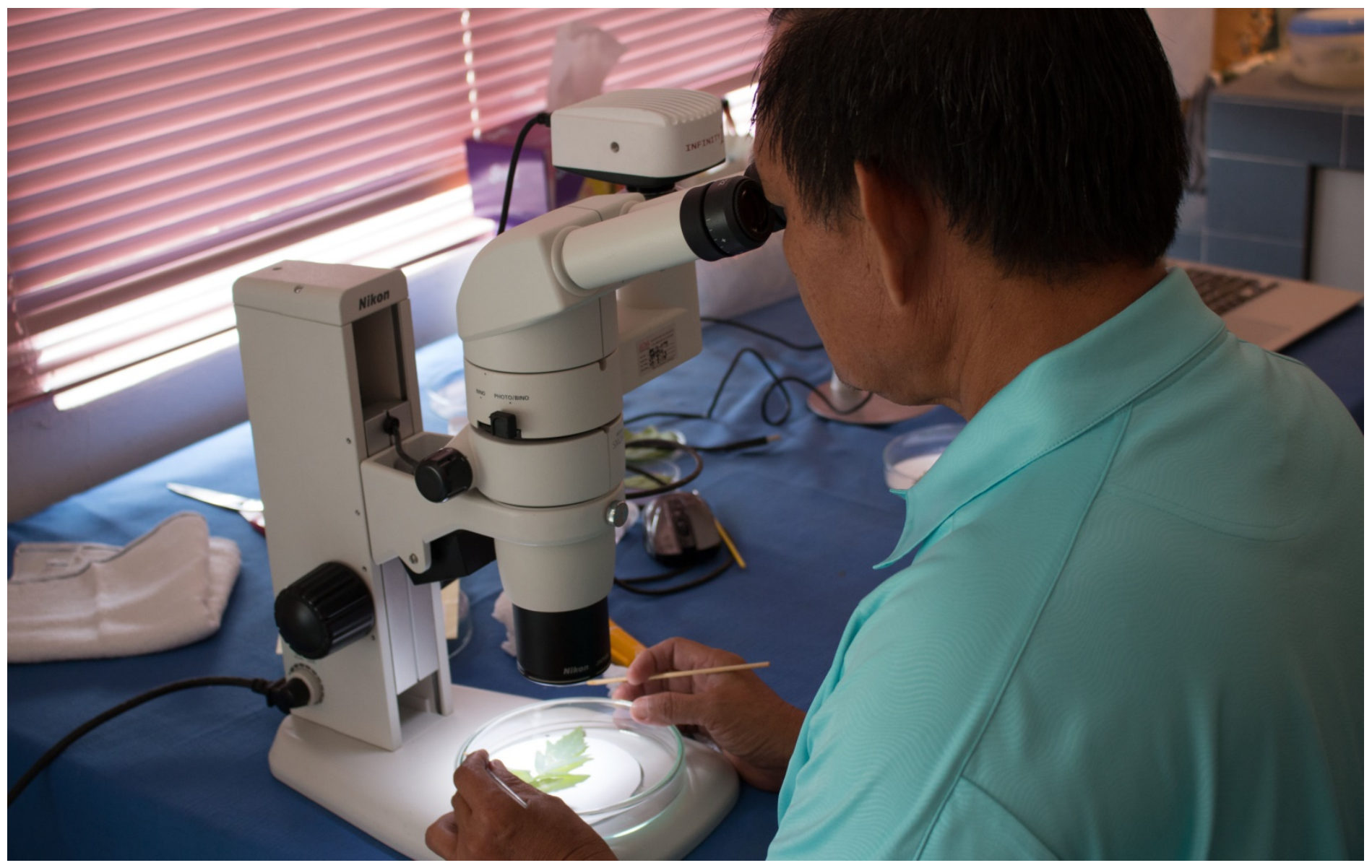

\section{CABI Policy and Guidelines for Proper Scientific Conduct in Research}




\section{CABI Policy and Guidelines for Proper Scientific Conduct in Research}

\section{Policy}

$\mathrm{CABI}$ has adopted the UK Council for Science and Technology universal ethical code for scientists ${ }^{1}$. CABI upholds and expects its staff to uphold the code's three principles, these being:

a. Rigour, Honesty and Integrity.

- Act with skill and care in all scientific work. Maintain up to date skills and assist their development in others.

- Take steps to prevent corrupt practices and professional misconduct. Declare conflicts of interest.

- Be alert to the ways in which research derives from and affects the work of other people, and respect the rights and reputation of others.

b. Respect for Life, the Law and the Public Good.

- Ensure their work is lawful and justified.

- Minimise and justify any adverse effect their work may have on people, animals and the natural environment.

c. Responsible Communications: Listening and Informing

- Seek to discuss the issues that science raises for society. Listen to the aspirations and concerns of others.

- Not knowingly mislead, or allow others to be misled, about scientific matters. Present and review scientific evidence, theory or interpretation honestly and accurately.

This document should be considered in conjunction with CABl's Code of Business Conduct ${ }^{2}$ and Intellectual Property Management Policy ${ }^{3}$, with which there is significant overlap, and CABI's Performance and Conduct Rules ${ }^{4}$ (which includes disciplinary rules and procedures) because scientific misconduct in research may include, but is not limited to, deviation from the Guidelines below.

\footnotetext{
${ }^{1}$ http://www. bis.gov.uk/cst/cst-reports

${ }^{2}$ http://intranet/Uploads/File/Intranet/STAFF\%20COUNCIL/CABICODEOFBUSINESSCONDUCT.pdf

${ }^{3}$ http://intranet/FullTextPDF/Alphabetical/IP ManagementPolicy101209-V1\%204.pdf

${ }^{4}$ http://intranet/FullTextPDF/Alphabetical/PerformanceandConduct.pdf
} 


\section{Guidelines}

1. It is the responsibility of every member of staff to uphold CABl's reputation and, consequently, it is expected that they will conduct research with integrity. These guidelines describe practices that have been established by several professions and generally accepted (see acknowledgements). Their purpose is to encourage the education and training of junior staff by senior colleagues and to ensure that the quality and integrity of research is maintained at CABI.

2. Research is defined as all research, scholarly and creative activity that supports the mission of CABI.

3. It is the responsibility of all relevant CABI Managers to ensure that these guidelines are promulgated in their area of responsibility and members of staff and students are aware of their obligations with respect to proper scientific conduct.

\section{Culture}

4. The preservation of research integrity must be largely dependent on self-regulation by CABI's scientists. The primary way to encourage appropriate conduct is to promote and maintain a climate consistent with high ethical standards. It is imperative that all members of $\mathrm{CABI}$, whether students, staff or administrators, recognise the responsibilities that they share for developing and maintaining a culture in which sound research practices are adopted and inappropriate ones detected. To do this, honesty, openness and guidance should be encouraged to ensure that professional standards are upheld.

\section{a. Honesty.}

(i) Regardless of scientific discipline and where based in CABI, the fundamental factor in ensuring the quality of research and research practices has to be the honesty of the individual investigator. Investigators should be honest with respect to their own work, which means subscribing to proper scientific practices such as acknowledging the contributions of colleagues or collaborators and ensuring veracity of data.

(ii) However, investigators are also expected to be honest in relation to the work of their colleagues and peers. Colluding in, or concealing, the misconduct of others is not compatible with an environment which encourages intellectual honesty and is, therefore, in itself misconduct. Every employee of CABI has a duty to inform the appropriate authorities if they know or suspect that there has been a breach of good conduct. The appropriate authority would normally be the line manager and/or Regional Director (or equivalent business director), but the Chief Scientist may also be informed.

\section{b. Openness.}

(i) $\mathrm{CABI}$ recognises the need for scientists to protect their own, their customers and sponsors, and CABI's research interests. $\mathrm{CABI}$ encourages its scientists to be as open as possible, while meeting the requirements of CABl's Intellectual Property Management Policy. This policy and the contractual arrangements for individual pieces of work may require confidentiality for a fixed or indefinite period.

(ii) This openness includes such common practices as the scholarly exchange of ideas and data and the submission of work to peer review or to another forum where it can be challenged and questioned without the loss of face. Such an environment is essential not only to the establishment of good scientific conduct, but to the development of good and 
innovative science itself. Openness also implies that all steps will be taken to avoid, or at least declare, conflicts of interest.

\section{c. Guidance.}

(i) These guidelines cannot and do not encompass every element of proper scientific conduct. For this reason CABI expects individual investigators, research and project groups to follow guidelines provided by other bodies which relate to their work. When in doubt about the ethics of proposed research, scientists should always refer these through line management to the appropriate level in CABI for specific guidance.

(ii) Investigators are also under an obligation to comply with all the legislation relevant to their field of study including that of external bodies such as, in the UK, the Health and Safety Executive, the Home Office, as well as the requirements of individual funding sources themselves and CABI policy such as CABI's Health and Safety Policy at each Regional Centre.

(iii) Of particular relevance to some aspects of CABl's research is the Nagoya Protocol on Access to Genetic Resources and the Fair and Equitable Sharing of Benefits Arising from their Utilization to the Convention on Biological Diversity ${ }^{5}$, and national legislation arising from it. Investigators and managers will comply with the legislation where present, and where legislation is not yet in place, follow the spirit of the protocol based on the good practice guidance of the Swiss Academy of Sciences ${ }^{6}$. In the absence of any legislation or regulation, normal practice should be based on working openly with a national agency or national university, and keeping a record of the support that they have received while working with $\mathrm{CABI}$.

5. Each relevant member of the CABI Senior Management Group, including in particular the Chief Scientist, Regional and Global Directors, should ensure that this culture is promulgated within their own area, by ensuring that these guidelines are brought to the attention of all staff (and to joining staff as part of the induction process), establishing mentoring relationships between senior scientists and new practitioners to guarantee the transmission of proper scientific standards, and monitoring and discussing with staff the implementation of these guidelines. Some of the RD role will be delegated to senior scientists in practice, especially in larger or mixed discipline centres.

\section{Supervision of Research}

6. The following recommendations refer to research students, junior members of the scientific staff and research assistants. These 'new investigators' often lack substantial experience and require significant input from their 'supervisors' to successfully understand complex scientific methods, interpret data, and to undertake statistical analysis.

a. Every new investigator working with $\mathrm{CABI}$ should be assigned at least one $\mathrm{CABI}$ supervisor who specialises in a relevant research area. This role will normally be combined with that of line manager, so where this is not the case, the respective roles of supervisor and line manager need to be made clear.

\footnotetext{
5 http://treaties.un.org/doc/source/signature/2010/Ch-XXVII-8-b.pdf

${ }^{6}$ Biber-Klemm, S.; Martinez, S. (2006) Access and benefit sharing. Good practice for academic research on genetic resources. Swiss Academy of Sciences, Bern, Switzerland. www.iisd.org/pdf/2006/abs swiss abs good practice.pdf
} 
b. The ratio of new investigators to supervisors and time allocated for supervision by senior staff should be such that close interaction and oversight of research is possible for the supervisor.

c. It is the responsibility of a supervisor to ensure that new investigators are aware of any relevant $\mathrm{CABI}$ regulations pertaining to their work, as well as the standards of conduct which are expected of them in their research. This should be formalised as part of the standard induction process for scientific staff at all CABI units.

d. The supervisor should oversee all aspects of the new investigators' work including the design of the research, whether it be experimental, theoretical or numerical and the process of acquiring, recording, examining and interpreting data; it is not acceptable for the supervisor to have a role which involves simply the editing of a new investigator's thesis or report.

e. Supervisors should emphasise the importance of keeping and maintaining an accurate record of research undertaken.

f. To encourage peer review, there should be regular communication within and between relevant research groups, for example through group meetings or dissemination of written work.

g. There should be regular internal meetings and external opportunities for new investigators to present, discuss and scrutinise work in progress and completed.

h. Students are also required to follow the regulations and procedures of the university where they are registered.

\section{Data Collection and Retention}

7. It is important that primary results are recorded accurately during research and they can be retrieved or reproduced if necessary ${ }^{7}$. For data which requires statistical analysis, the same methodology should be used in the design of the research as in its evaluation. The existence of verifiable data will allow research results to be tested by a third party if an allegation of scientific misconduct is made. Accordingly:

a. The investigator should consult other specialists before conducting the research, particularly if some aspects of a study are outside the expertise of the investigator.

b. Primary data should be recorded promptly, accurately and permanently by an appropriate method. Entries should be signed and dated by the investigator where possible. This is consistent with the requirements of patent law, and will provide protection from allegations of misconduct as well as having positive benefits for the individual researcher. In areas where there is the potential for exploitable IP to be generated IP notebooks should be used and CABI IP policy on records should be followed in full.

\footnotetext{
${ }^{7} \mathrm{CABI}$ will establish an internal repository and procedures to capture scientific data electronically, in which research data and other scientific outputs will need to be deposited, probably as part of the $\mathrm{CABI}$ Project Management System. Details will be added to these guidelines as this mechanism is developed and put in place.
} 
c. Where computer and/ or instrument printouts are the main record of results, these should be kept in numerical order and affixed to any relevant laboratory notebooks.

d. Any changes made to primary data during the conduct of a study should be identified separately and the reason for the change should be indicated. Under no circumstances should data be modified in an improper manner.

e. Primary data are the property of $\mathrm{CABI}$, except as may be specified in funding contracts for the research, and should remain in the Regional Centre where they were generated for as long as reference needs to be made to them and for no less than ten years or until they are fully archived electronically.

\section{Authorship}

8. CABI expects that all scientific activities carried out by staff will be documented, and published as appropriate, so as to make the results available. At the least, a technical report should be prepared for appropriate dissemination, if not restricted due to confidentiality agreements or the requirements of the CABI Intellectual Property Management Policy. When this leads to a peer-reviewed scientific publication, this should be made open access as far as practical.

9. Authorship of reports and papers based on scientific research should follow normal protocols for authorship:

a. All co-authors should have made a significant contribution to the work reported, including an intellectual contribution to one or more of design, analysis and interpretation. All authors will normally contribute to the writing, editing and review; there should be no honorary authorships. Routine collection of data, data entry, compiling references, getting funding, and facilitation are examples of contributions that could or should be acknowledged rather than justify authorship.

b. Where there are two or more co-authors involved in a study, it is suggested that one author takes responsibility for the scientific accuracy of the entire publication (normally the author for correspondence). This lead author should verify that each co-author has reviewed the manuscript and is able to confirm that their area of expertise is accurate to the best of their knowledge. All authors should agree the publication before submission or release.

c. Authorship and order of authorship should be discussed and agreed as early in the process as practical; remember it is easier to add an author than remove one. Authors should not be included without their agreement.

10. Regional Directors have a responsibility to ensure that members of the Centre are not engaged in the publication of research which is not authentic. Regional Directors may require internal review of papers before submission (in consultation with the Chief Scientist as needed).

\section{Acknowledgements in publications and reports}

11. The acknowledgement section of publications and reports is a formal statement that recognises funding bodies, institutions, departments and individuals (non-coauthors) for their particular contributions to the research being reported. By acknowledging all support to your research, you are demonstrating your integrity as a researcher, which consequently encourages continued collaboration and support. Therefore you should mention the 
following individuals/institutions:

a. Individuals who provided scientific guidance, including advice on data analysis

b. Individuals who gave critical feedback on the paper during its drafting and revising stages

c. Those who shared unpublished results

d. Persons/institutions that provided facilities/equipment

e. Persons or institutions who provided certain data, protocols, images, specific reagents or samples

f. Technicians and lab assistants who provided technical support

g. Funding agencies/donors. We are required by all our donors to acknowledge their financial support.

Needless to say that none of our research outputs would have been possible without the generous financial support of our donors. Therefore, in addition to specific acknowledgments (a-f above), ALL CABI scientists, visiting scientists, post- doctoral scientists, and graduate students are required to include the following funding acknowledgment statements in ALL $\mathrm{CABI}$ authored publications (peer reviewed journal articles, brochures, posters), PowerPoint presentations and press releases (excluding materials publishing or promoting books and resources authored outside of CABI's responsibility):

We gratefully acknowledge the funding provided for this research by the following organizations and agencies: [list the relevant donors/sponsors (with contract number(s) if allocated)]

$C A B I$ is an international intergovernmental organisation, and we gratefully acknowledge the core financial support from our member countries (and lead agencies) including the United Kingdom (Department for International Development), China (Chinese Ministry of Agriculture), Australia (Australian Centre for International Agricultural Research), Canada (Agriculture and Agri-Food Canada)), Netherlands (Directorate-General for International Cooperation), and Switzerland (Swiss Agency for Development and Cooperation). See http://www.cabi.org/about-cabi/who-we-workwith/key-donors/ for full details.

\section{Acknowledgements}

$\mathrm{CABI}$ wishes to gratefully acknowledge the use of the following document in writing this paper:

Imperial College of Science, Medicine and Technology (2006) Guidelines for Proper Scientific Conduct in Research, which itself was based on:

- Faculty of Medicine Harvard University (1996) Guidelines for Investigators in Scientific Research.

- icipe's acknowledgements policy. 
Africa

Ghana

CABI, CSIR Campus

No.6 Agostino Neto Road

Airport Residential Area

P.O. Box CT 8630,

Cantonments

Accra, Ghana

T: +233 (0)302 797202

E:westafrica@cabi.org

Kenya

CABI, Canary Bird

673 Limuru Road,

Muthaiga

P.O. Box 633-00621

Nairobi, Kenya

T: +254 (0)20 2271000/20

E:africa@cabi.org

Zambia

CABI, Southern Africa

Centre

5834 Mwange Close

Kalundu, P.O. Box 37589

Lusaka, Zambia

T: +260967619665

E: southernafrica@cabi.org
Americas

Brazil

CABI, UNESP-Fazenda

Experimental Lageado,

FEPAF (Escritorio da

CABI)

Rua Dr. Jose Barbosa De

Barros 1780

Fazenda Experimental

Lageado

CEP: 18.610-307

Botucatu, San Paulo, Brazil

T: +55 (14) 38807670

E: y.colmenarez@cabi.org

Trinidad \& Tobago

CABI, Gordon Street,

Curepe

Trinidad \& Tobago

T: +1 8686457628

E: caribbeanla@cabi.org

\section{USA}

CABI, 745 Atlantic Avenue 8th Floor

Boston, MA 02111

$\mathrm{T}:+1$ (617) 682-9015/ +1

(617) 682-9016

E: h.jansen@cabi.org
Asia

China

CABI, Beijing

Representative

Office

Internal Post Box 85

Chinese Academy of

Agricultural Sciences

12 Zhongguancun Nandajie

Beijing 100081, China

T: +86 (0)10 82105692

E: china@cabi.org

India

CABI, 2nd Floor, CG Block, NASC Complex, DP

Shastri Marg

Opp. Todapur Village,

PUSA

New Dehli - 110012, India

T: +91 (0)11 25841906

E: india@cabi.org

\section{Malaysia}

CABI, PO Box 210

43400 UPM Serdang

Selangor, Malaysia

T: +60(0)3 894329321

E: cabisea@cabi.org

\section{Pakistan}

CABI, Opposite 1-A,

Data Gunj Baksh Road

Satellite Town, PO Box 8

Rawalpindi-Pakistan

T: +92 51929 2064/ 2063 /

2062

E: cabi.cwa@cabi.org

\section{Europe}

\section{Switzerland}

CABI, Rue des Grillons 1

$\mathrm{CH}-2800$ Delemont

Switzerland

T: +41 (0)32 4214870

E: europe-ch@cabi.org

\section{Head Office}

CABI, Nosworthy Way

Wallingford, Oxfordshire

OX10 8DE, UK

$\mathrm{T}:+44$ (0)1491 832111

E: corporate@cabi.org

UK (Egham)

CABI, Bakeham Lane

Egham, Surrey

TW20 9TY, UK

T: +44 (0)1491 829080

E: microbialservices@cabi.org

E: cabieurope-uk@cabi.org 